\title{
EFFECTS OF NONUNIFORM SURFACE HEAT FLUX AND UNIFORM VOLUMETRIC HEATING ON BLANKET DESIGN ROR FUSION REACTORS
}

Mohammad Z. Hasan

UC:A/PPG- -1046

May 1988

\section{DISCLAIMER}

\begin{abstract}
This report was prepared as an account of work sponsored by an agency of the United States Government. Neither the United States Government nor any agency thetcof, nut any of their employees, makes any warranty. express or implied, or assumes any legal liability or responsibility for the accuracy, completeness. or use [ulness of any information. apparalus, product, or process disclosed, or represents that its use would not infringe privately owned rights. Reierence herein to any specilic commercial product, process, or servioe by trade name. Irademark. manufacturer, or otherwise daes not necessarily constitute or imply its endorsement. recommendation, of favoring by the United States Government of any agency thereof. The views and opinions of authors expressed herein do not necessurily state or reflecl those of the United States Government or any agency theteof.
\end{abstract}

Department of Mechanical, Aerospace, and Nuclear Engineering and Institute for Plasma and Fusion Research

University of California, Los Angeles

Los Angeles, CA 90024-1597 


\title{
EFFECTS OF NONUNIFORM SURFACE HEAT FLUX AND UNIFORM VOLUMETRIC HEATING ON BLANKET DESIGN FOR FUSION REACTORS
}

\author{
Mohammad Z. Hasan \\ Department of Mechanical, Aerospace, and Nuclear Engineeriug \\ and lustitute for Plasma and Fusion Research \\ University of Califormia, Los Aujgeles \\ Los Angeles, CA 90024-1597
}

\begin{abstract}
An analytical solution for the tempenature pmfile and film tempernture drop for fully-developed, laminar flow in a cinctslar tube is protided. The surface heat flux varies circumferentially but is canstant along the axis of the tube. The volumetric heat genemtion is uniform in the fuid. The fully developed laminar velocity profile is appmximated by a power velocity profile to represent the flattening effect of a perpendicular magnetic field when the coolant is electrically conductive. The presence of volumetric heat genemtion in the fluid adds another component to the film tempenture drop to that due to the surface heat flux. The reduction of the boundary layer thichness by a perpendicular magnetic feld reduces both of these twa film temperature drops. The Nusselt number for constant surface heat flux increases from 4.36 for parabolic velocity profile to 8 for nearly flat velocity profile or slug flow. The corresponding increase in the Nusselt number for uniform volumetric heat generation is from 2.46 to 5.33. A strong perpendicular magnetic field can neduce the film temperature drop by a factor of two if the fiuid is electrically conducting. The effect of nonuniformity of the surface heat flux, howevcr. is to reduce the Nusselt number or increase the film temperature drop at the location of the maximum heat fux compared to the case of uniforii surface heat flux. At the point of maximum surface heat fiux with a cosine variation, which is very close to the case of a coolant tube in the first wall and limiter/divertor plate of a fusion reactor, the Nusselt rumber can be nedtced from 4.36 to 2.7 and from 8 to 3 for patabolic and flat velocity profiles. respectively. The effect of perpendicular magnetic field /or the flatness of the velocity profile) is less pronounced on the film temperature drop due to nonuniform surface heat flux than on that due to uniform surface heat flux. An example is provided to show the relative effects of these two first temperature drops in the thermal design of fusion reactorg.
\end{abstract}




\section{INTRODUCTION}

There are situations where the heat flux on the surface of a coolant clamel is uonuniform and, at the sane tine, volumetric heat is generated in the conlant flowing through a coolant channel. An example of this is a coolant chanuel in the first wall and liniter/divertor plate of a fusion reactor. The side of the coolant chansel which faces the plasma receives radiation heat flux. Fusion neutrons generate volumetric heat in the structural material and coolant. In a fission reactor using liquid fuel, large volumetric heat is generated due to the fission reaction. The heat is removed through the channel wall and/or by the fuel shurry acting also as the coolant. Film temperature drop for such a case was determined by Popendiek $\{1\}$. Even with uiiform volumetric heat generation, there is a temperature drop across the boundary layer because fluid velocity is smaller in the boundary layer near the wall and hence part of the heat needs to be conducted to the central fluid which then convects away the heat. Reynolds $[2]$ treated the film temperature drop for the case of nonuniform surface heat flux on a circular tube witl parabolic velocity profile of the fluid.

Liquid metals, particuarly liquid lithium, are considered as coolants in fusion reactor applications. Liquid lithium was proposed as a coolant for fusion reactors by Holroyd and Mitchell [3] and Hunt and Hancox [4]. A recent reversed-field pinch reactor study, TITAN [5], has used liquid lithium as the primary coolant in one version of the design of the fusion reactor core. Since liquid metals are electrically conducting, the presence of any transverse magnetic field will affect the coolant velocity profile and hence the film temperature drop.

In the thermal-hydraulic design for a fusion reactor, the maximum structure temperature of a coolant channel is one of the design limits. Accurate determination of the structure temperature is, therefore, necessary for a safe design. The film temperature drops directly affect the channel-wall temperature. It is highly desirable to quantify the effects of magnetic field, volumetric heat generation and 
nonuniformity of surface heat Hux on the film temperature drop for liquid-metal as well as nonconducting fluid flow through the coolant channel in a fusion reactor.

The objectives of this work are to find analytical estimates for these effects. The analytical solution uses several assumptions. The coolant channel is taken to be circular tube. The flow is assumed laminar and fully developed. Power velocity profile is used to approximate the flattening of the velocity profile by a perpendicula: magnetic field. The magnetic field is transverse to a coolant channel rather thas radial in fusion applications and the channel cross section may be non-circular. The analytical results will, therefore, be approxinate. In section $I$, the analytical solutions are derived. The analytical results and examples of application to fusion reactors are discussed in section III. Conclusions and recommendations are given in section IV.

\section{TEMPERATURE PROFLE AND FILM TEMPERATURE DROP}

The steady-state, non-lımogeneous energy equation in cylindrical coordinates $(r, \theta, z)$ can be written as

$$
k_{,}\left(\frac{\partial^{2} T}{\partial r^{2}}+\frac{1}{r} \frac{\partial T}{\partial r}+\frac{1}{r^{2}} \frac{\partial^{2} T}{\partial \theta^{2}}\right)=\rho c_{p} u(r) \frac{\partial T}{\partial z}-q_{f}^{\prime \prime \prime}
$$

where $k_{f}$ is the thermal conductivity of the Huid, $T$ is the temperature, and $\rho$ and $c_{p}$ are the density and specific heat of the fluid, respectively. The uniform volumetric heat generation is denoted by $q_{f}^{\prime \prime \prime}$ and the fully developed velocity profile is represented by $u(r)$. It is assumed that the surface heat flux and the volumetric heat generation do not vary along the axis of the tube. Therefore, $T$ is a linear function of the axial coordinate, $z$. The magnetic field is assumed to be uniform and perpendicular to the coolant flow (such as a uniform radial magnetic field). In this case, the velocity profile will be flattened uniformly along the circunference. and there will not be any $\theta$-dependence as is the case with a transverse magnetic field [6]. The velocity profile can then be approximated by the following equation. 


$$
u(r)=\frac{m+2}{m} U\left\{1-\left(\frac{r}{a}\right)^{m}\right\}
$$

where $U$ is the mean velocity and $a$ is the inner radius of the tube. The power index, $m$, increases with the increase of perpendicular Hartmann umuber. For $m=2$, the velocity profile is parabolic corresponding to zero Hartmann number. The mean velocity is given by

$$
U=\frac{2}{a^{2}} \int_{0}^{a} u(r) r d r
$$

Solution to equation (1) will be obtained for surface heat flux which varies arbitrarily along the circumference. The procedure adopted is similar to that in ref.[2]. Figure 1 shows the three steps involved in the solution. The boundary and symuletry conditions are shown in Fig. la. First, equation (1), with houndary and symmetry conditions, is solved for the case shown in Fig. 1a where the surface heat flux $q^{\prime \prime}>0$ for $-\beta \leq \theta \leq \beta$, and $q^{\prime \prime}=0$ on the rest of the circumference. Second, by superposition of the result in the previous step, solution with segmental heating, as shown in Fig. Ib, is obtained. Finally, in the limit, replacing the summation in the previous step by integration, the desired solution for the case of arbitcary surface heat flux, Fig. 1c, is obtained.

Let $T_{f}(z)$ be the mean fiuid temperature and $r$ be normalized by the inmer radius of the tube. By energy balance for the case (a) in Fig. 1, we get

$$
\frac{d T}{d z}=\frac{d T_{f}}{d z}=\left(\frac{2 \beta q^{\prime \prime}}{\pi a \rho c_{p} U I}+\frac{q_{f}^{\prime \prime \prime}}{\rho c_{p} U}\right)
$$

Using this axial derivative and the velocity profile, equation (2), in equation (1), we get.

$$
\frac{\partial^{2} T}{\partial r^{2}}+\frac{\partial T}{\partial r}+\frac{1}{r^{2}} \frac{\partial^{2} T}{\partial \theta^{2}}=\frac{m+2}{m}\left(1-r^{m}\right) \frac{2 a \beta q^{\prime \prime}}{\pi k_{f}}+\left\{\frac{m+2}{m}\left(1-r^{m}\right)-1\right\} \frac{a^{2} q_{f}^{\prime \prime \prime}}{k_{f}} .
$$


Since the quantity we are interested in is the filu tenperature drop, we define $\Delta T(r, \theta)=T(r, \theta, z)-T_{f}(z)$. Let

$$
\Delta T(r, \theta)=F(r, \theta)+g(r)
$$

where $F(r, \theta)$ is the homogeneous solution and $g(r)$ is the particular solution. Inserting equation (4) in equation (3) and equating the right hand side with the particular solution, we get

$$
\frac{\partial^{2} F}{\partial r^{2}}+\frac{1}{r} \frac{\partial F}{\partial r}+\frac{1}{r^{2}} \frac{\partial^{2} F}{\partial \theta^{2}}=0
$$

and

$$
\frac{d^{2} g}{d r^{2}}+\frac{1}{r} \frac{d g}{d r}=\frac{m+2}{m} \frac{2 a \beta q^{\prime \prime}}{\pi k_{f}}\left(1-r^{m}\right)+\frac{a^{2} q_{f}^{\prime \prime}}{k_{f}}\left\{\frac{m+2}{m}\left(1-r^{m}\right)-1\right\}
$$

The solution for the particular component, $\mathrm{g}(\mathbf{r})$, is obtained as

$$
g(r)=\frac{m+2}{m}\left\{\frac{r^{2}}{4}-\frac{r^{m+2}}{(m+2)^{2}}\right\}(\dot{s}+B)-B \frac{r^{2}}{4}+C_{1}^{\prime} \ln r+C_{2},
$$

where $A=\frac{2 \mathrm{c} \beta q^{\prime \prime}}{\pi k_{t}}, B=\frac{a^{2} q_{i}^{\prime \prime \prime}}{k_{j}}$, and $C_{1}$ and $C_{2}$ are constants of integration. $C_{1}=0$ to make $g(r)$ finite ai $r=0$ and $C_{2}$ can be absorbed in the holiogeneous solution, $F$. The solution for $g(r)$ then becomes

$$
g(r)=\frac{m+2}{m}\left\{\frac{r^{2}}{4}-\frac{r^{m+2}}{(m+2)^{2}}\right\}(A+B)-B \frac{r^{2}}{4}
$$

The solution for $F(r, \theta)$ is obtained by separation of variables. It is given by

$$
F(r, \theta)=c_{0}+\sum_{n=1}^{\infty} c_{n} r^{n} \cos n \theta
$$

where $c$ 's are constants and $n$ is the eigenvalue. Now arlding equations (5) and $(6)$, we get the expression for $\Delta T(r, \theta)$. 


$$
\Delta T(r, \theta)=(A+B) \frac{m+2}{m}\left\{\frac{r^{2}}{4}-\frac{r^{m+2}}{(m+2)^{2}}\right\}-\frac{r^{2}}{4}+c_{0}+\sum_{n=1}^{\infty} c_{n} r^{n} \cos n \theta .
$$

The constants $c_{n}$ can be determined by using the boundary conditions on $F(r, \theta)$ and the orthogonality condition.

The boundary conditions on $T$ for the case (a) in Fig, 1 are:

$$
\frac{\partial T}{\partial r} i_{r=1}= \begin{cases}\frac{a q^{\prime \prime}}{k_{f}} & ;-\beta \leq \theta \leq \beta \\ 0 & ; \beta \leq \theta \leq \beta\end{cases}
$$

The boundary conditions on $F(r, \theta)$ can be obtained from the equations $(4),(5)$ and $(\bar{r})$.

$$
\left.\frac{\partial F}{\partial r}\right|_{r=1}=\left.\frac{\partial \Delta T}{\partial r}\right|_{r=1}-\left.\frac{d g}{d r}\right|_{r=1}
$$

This gives

$$
\left.\frac{\partial F}{\partial r}\right|_{r=1}=\left\{\begin{array}{ll}
\frac{a q^{\prime \prime}}{k_{f}}\left(1-\frac{a}{\pi}\right) & ;-\beta \leq \theta \leq \beta \\
-\frac{a q^{\prime \prime} \beta}{\pi k_{f}} & ; \beta \leq \theta \leq 2 \pi-\beta
\end{array} .\right.
$$

Now we differentiate equation (6) with respect to $r$, multiply it by $\cos m \theta$ and then integrate over $\theta$ from 0 to $2 \pi$ using orthogonality and the boundary conditions to obtain

$$
c_{n}=\frac{2 a q^{\prime \prime} \sin n \beta}{\pi \pi^{2} k_{f}} ; n \geq 1
$$

Equation (7) now becomes

$\Delta T(r, \theta)=c_{o}+\frac{2 a q^{\prime \prime}}{\pi k_{f}} \sum_{n=1}^{\infty} \frac{r^{n}}{n} \sin n \beta \cos n \theta+(A+B) \frac{m+2}{m}\left\{\frac{r^{2}}{4}-\frac{r^{m+2}}{(m+2)^{2}}\right\}-B \frac{r^{2}}{4}$.

The remaining constant $c_{o}$ can be determined by equating the average of the difference of the fluid temperature from the mean fluid temperature to zero. That is, from

$$
\int_{0}^{1} \int_{0}^{2 \pi} u(r) \Delta T\left(r_{,} \theta\right) r d r d \theta=0
$$


From equation (9), using equations (2) and (8), $c_{v}$ is obtained as

$$
c_{0}=-(A+B) \frac{m^{2}+6 m+12}{8(m+4)(m+2)}+B \frac{(m+2)(m+3)}{2 m(m+4)} .
$$

The film temperature drop, $\Delta T_{f}(\theta)$, is obtained by putting $r=1$ in equation (8) and using the expressions for $c_{o}, A$ and $B$. This gives

$$
\begin{gathered}
\Delta T_{f}(\theta)=\frac{2 a q^{\prime \prime} \beta}{k_{f} \pi}\left(\frac{m^{2}+10 m+20}{8 m^{2}+48 m+64}\right)+\frac{2 a q^{\prime \prime}}{k_{f} \pi} \sum_{n=1}^{\infty} \frac{1}{n^{2}} \sin n \beta \cos n \theta \\
+\frac{a^{2} q_{f}^{\prime \prime \prime}}{k_{f}}\left(\frac{3 m^{3}+26 m^{2}+68 m+48}{8 m^{3}+48 m^{2}+64 m}\right) .
\end{gathered}
$$

Now if the heat flux is only on a small segment of the surface of the tube as shown in case (b) of Fig. I, the film temperature drop due to this small segmental heat flux, $\delta T_{f}(\theta)$, can be obtained by replacing $\beta$ by $\Delta \omega / 2$ and $\theta$ by $(\theta-\omega-\Delta \omega / 2)$ in equation (10). Thus we obtain

$$
\begin{aligned}
\delta T_{f}(\theta)= & \frac{2 a q^{\prime \prime}}{k_{f}} \frac{\Delta \omega}{2 \pi}\left(\frac{m^{2}+10 m+20}{8 m^{2}+48 m+64}\right)+\frac{2 a q^{\prime \prime}}{k_{f} \pi} \sum_{n=1}^{\infty} \frac{1}{n^{2}} \sin \frac{n \Delta \omega}{2} \\
& \cos n\left(\theta-\omega-\frac{\Delta \omega}{2}\right)+\frac{a q_{f}^{\prime \prime}}{k_{f}}\left(\frac{3 m^{3}+26 m^{2}+68 m+48}{8 m^{3}+48 m^{2}+64 m}\right) .
\end{aligned}
$$

If there are $L$ small segments with surface heat flux, then the total film temperature drop can be obtained by superposition of the result in equation (11).

$$
\Delta T_{f}(\theta)=\sum_{\ell=1}^{L} \delta_{\ell} \Delta T_{f}(\theta)
$$

The summation is only over the first two terms in equation (11). For the case of continuous variation of surface heat flux, case (c) in Fig. 1, the film temperature drop can be obtained by replaxing $\sum_{t=1}^{L}$ by $\int_{n}^{2 \pi} d w$ and approxinating $\sin \frac{n \Delta w}{2}$ by $\pi d w / 2$ in equation (11) and (12). Doing this, we get

$$
\begin{gathered}
\Delta T_{f}(\theta)=\frac{a}{\pi k_{f}}\left(\frac{m^{2}+10 m+20}{8 m^{2}+48 m+64}\right) \int_{0}^{2 \pi} q^{\prime \prime}(\omega) d \omega-\frac{a}{\pi k_{f}} \int_{0}^{2 \pi} q^{\prime \prime}(\omega) \\
\ln \left\{2 \sin \frac{\theta-\omega}{2}\right\} d \omega+\frac{a^{2} q_{f}^{\prime \prime}}{k_{f}}\left(\frac{3 m^{3}+26 m^{2}+68 m+48}{8 m^{3}+48 m^{2}+64 m}\right) . \\
-7-
\end{gathered}
$$


ln equation $(13)$, the series

$$
\sum_{n=1}^{\infty} \frac{1}{n} \cos n(\theta-\omega)
$$

is replaced by [7]

$$
-\ln \left\{2 \sin \frac{(\theta-\omega)}{2}\right\}
$$

In equation (13), the first two terms represent the fim temperature drop, $\Delta T_{s}(\theta)$, due to arbitrarily varying surface heat flux. The last term represents the film temperature drop, $\Delta T_{v}$, due to the uniform volumetric heat generation in the coolant. Although the volumetric heat generation rate is uniform in the coolant, the film temperature drop $\Delta T_{v}$ arises because of the presence of boundary layer. Coolant velocity is zero at the surface of the wall and it increases into the boundary layer away from the wall. Therefore, there is a gradual decrease in axial convection of heat from the center to the wall of the tube. As a result, coolant temperature increases towards the wall and heat condincts to the center of the tube to be convected by the faster moving coolant. A Nusselt number for the surface leat flux can be defined by the following equation.

$$
N u_{s}(\theta)=\frac{(2 a) q^{\prime \prime}(\theta)}{\Delta T_{s}(\theta) k_{f}}
$$

An equivalent Nusselt number for the volumetric heat generation can be defined as

$$
N u_{v}=\frac{(2 a)\left(a q_{f}^{\prime \prime \prime}\right)}{\Delta T_{v} k_{f}}=\left\{\frac{2\left(8 m^{3}+48 m^{2}+64 m\right)}{3 m^{3}+26 m^{2}+68 m+48}\right\} .
$$

In equation (15), $\left(a q_{f}^{\prime \prime \prime}\right)$ is equivaleni to heat flux.

Familiar results for Nusselt number can be obtained from the above equations. For uniform surface heat flux, $\beta=\pi$. The film temperature drop corresponding to constant surface heat flux becomes, from equation (13), 


$$
\Delta T_{s}=\frac{2 a q^{\prime \prime}}{k_{f}}\left(\frac{m^{2}+10 m+20}{8 m^{2}+48 m+64}\right)
$$

The Nusselt number is then given by

$$
N u_{s}=\frac{8 m^{2}+48 m+64}{m^{2}+10 m+20}
$$

In the absence of any transverse component of magnetic field, the fully developed laminar velocity profile is parabolic $(m=2)$, Equation (16) then gives $N \imath_{\mathrm{s}}=48 / 11=4.36$, which is the Nusselt number for constant, heat flux and parabolic velocity profile in a circular tube. When the perpendicular Hartmann number is very large, the velocity profile is nearly flat like that for slug flow. In the limit $m$. approaches infinity, equation (16) gives $N u_{s}=8$, which is the Nusselt number for slug flow in a circular tube with constant surface heat flux. Nusselt number defined for the film te:aperature drop due to the uniform volumetric heat generation, equation (15), has the value of $32 / 13=2.46$ for parabolic velocity profile $(m=2)$ and $16 / 3=5.33$ for slug flow (large $m$ ). Therefore, a strong magnetic field perpendicular to the flow of an electrically conducting coolant will reduce the film temperature drops due to uniform surface heat flux and volvmetric heat generation by a factor of about two. When the surface heat flux varies along the circunference, then the film temperature drop and the Nusselt number due to the surface heat flux will be functions of 9 . In the next section, we discuss the effects of the flat.ness of velocity profile and the variztion of surface heat flux on Nusselt number by using specific examples from fusion reactor application. 


\section{RESULTS AND DISCUSSION}

Coolant channels with circular cross sections are often used in fusion reactor thermal-hydraulic design because circular tubes have good heat transfer perforinance, high structural strength, and are easy to manufacture with close tolerance [5]. Figure 2 shows the cross section of a first-wall coolant tube used in the thermal-hydraulic design of the fusion power core of the reversed-field-pinch fusion reactor, TITAN-I [5]. The tube material is the vanadium alloy, V-3Ti-1Si, and the coolant is liquid lithium. The inner radius of the tube is $4 \mathrm{~mm}$ and its outer radius is $5.05 \mathrm{tnm}$. The radiation heat flux incident on the surface of the first-wall tube facing the plasma is denoted by $q_{R}^{\prime \prime}$ and the volumetric nuclear heat generation rates in the tube wall and lithium are represented by $q_{u \prime}^{\prime \prime \prime}$ and $q_{f}^{\prime \prime \prime}$, respectively. Neutron wall loading of TITAN-I is $18.1 \mathrm{MW} / \mathrm{m}^{2}$. The nuclear heat generation at the first wall are $q_{w}^{\prime \prime \prime} \simeq 100 \mathrm{MW} / \mathrm{m}^{3}$ and $q_{f}^{\prime \prime \prime} \simeq 75 \mathrm{MWV} / \mathrm{m}^{3}$. At the design point where $95 \%$ of the alpha and olmic dissipatize power in the plasma is radiated, the radiation heat flux on the first wall is $4.6 \mathrm{MW} / \mathrm{m}^{2}$. At different wall loading or different radiation fraction, the heat flux on the first wall will have different values. The effects of nonuniformity of the sirface heat fux and the flatness of the velocity profile caused by perpendicular magnetic field, on heat transfer will be presented in this section. The first-wall coolant channel of TITAM-I will he used as example.

The surface heat flux on the inn $r$ surface of a first-wall tube can be writ ten as

$$
q^{\prime \prime}(\theta)= \begin{cases}q_{N y}^{\prime \prime}+\frac{b}{a} q_{R}^{\prime \prime} \cos \theta & ;-\frac{\pi}{2} \leq \theta \leq \frac{\pi}{2} \\ q_{N F}^{\prime \prime} & ; \frac{\pi}{2} \leq \theta \leq \frac{3 \pi}{2}\end{cases}
$$

where

$$
q_{N H}^{\prime \prime}=\frac{q_{w}^{\prime \prime \prime}\left(b^{2}-a^{2}\right)}{2 a} .
$$

The outer radius of the coulant channel is $b$. Equation (17) assumes that the radiation heat flux is cosine on the tube surface and that conduction in the tube wall along $\theta$ is negligible. 
The total film temperature drop duc to nonuniform surface heat flux and uniform volumetric heat generation is given by equation (13). Equations (15) and (16) determine the Nusselt numbers fer uniform volumetric heat generation in the coolant and constant surface heat flux, respectively, as functions of the porer index $(m)$ of the velocity profile. Figure 3 shows this variation. At $m=2$, for parabolic profile, $N u_{s}=48 / 11$ due to constant surface heat flux and $N i_{v}=32 / 13$ due to uniform volumetric heat genea ation. As $m$ increases, $N u$ approaches the slug-flow magnitudes of 8 and $16 / 3$ for the uniform surface heat flux and volumetric heat generation, respectively. This shows that whenever a perpendicular magnetic field flattens the velocity profile, thus reducing the boundary layer thickness, heat . transfer will become better and film temperature drop will decrease.

The effect of circumferential variation of surface heat flux is shown in Fig. 4. The value of $m$ is 250 which gives nearly slug flow corresponding to high perpendicular Hartmann number ( $\geq 200$ ). The surface heat flux is given by equation (17) with $q_{R}^{\prime \prime}=4.6 \mathrm{MW} / \mathrm{m}^{2}$ and $q_{w}^{\prime \prime \prime}=100 \mathrm{MW} / \mathrm{m}^{3}$. The tube dimensions are the same as those for the first-wall tube for TITAN-I. The Nusselt number is the smallest at $\theta=0^{\circ}$ where the radiation heat flux is the maximum. The value of Nusselt number at $\theta=0^{\circ}$ is about 3. It is much less than 8 for constant heat flux. At about $85^{\circ}, N u$ becomes infinite. The reason is that at this point the wall/coolant interface temperature becomes equal to the mean coolant temperature thus making the film temperature drop zero. Beyond this point, $N u$ is negative. Negative Nusselt number means that the mean coolant temperature is higher than the interface temperature so that the film temperature drop becomes negative. A schematic representation of the temperature profile which explains this is shown in Fig. 5. When the Nusselt number is negative, the magnitude of the film temperature drop has to be subtracted from the mean fluid temperature to obtain the temperature at the inner surface of the wall of the coolant tube.

Figure 6 shows the variation of $N u$ with $m$ at $\theta=0$ and peak radiation heat flux 
of $q_{R}^{\prime \prime}=4.6 \mathrm{MW} / \mathrm{m}^{2}$. The uniform lieat flux at the inner surface of the tube due to volumetric heat generation in tlue tube wall, $q_{N H}^{\prime \prime}$, is $0.145 \mathrm{MW} / \mathrm{m}^{2}$. This is about. 32 times smaller than the peak radiation heat fux at $\theta=0$. Under this condition of highly peaked surface heat flux, the increase in $N u$ in going from parabolic to nearly flat velocity profile is very small, only $10 \%(2.7$ to 3.0$)$ compared to about $85 \%$ (4.36 to 8 ) increase for the case of constant heat flux. This means that when the surface heat flux is lighly peaked, perpendicular magnetic field, however large, does increase very little the $N u$ at the critical point of peak heat flux, that is, at $\theta=0^{\circ}$ under the present condition. This will liave significant impact on the thermalhydraulic design of the first wall, divertor and limiter of a fusion reactor using liquid metal as coolant.

The effects of peakedness of the surface heat flux on the Nusselt number for parabolic $(m=2)$ and nearly flat $(m=250)$ velocity profiles are shown in Fig. 7 . In this figure, $N u\left(\theta=0^{\circ}\right)$ is plotted against $q_{R}^{\prime \prime} / q_{N H}^{\prime \prime}$. The ratio $q_{R}^{\prime \prime} / q_{N H}^{\prime \prime}$ is a measure of the peakedness of the surface heat flux. The heat flux at the inner surface of the tube wall due to the nuclear lieating in the wall, $q_{N H}^{\prime \prime}$, is constant along the circumference. The peak radiation heat flux, $q_{\AA}^{\prime \prime}$, is varied to change the ratio. The curve for $m=250$ simulates the flattening of the velocity profile of a conducting fluid by a perpendicular magnetic field. At $q_{R}^{\prime \prime} / q_{N H}^{\prime \prime}=0, N u=8$, the case for constant heat flux and slug flow. The Nusselt number at $\theta=0^{\circ}$ decreases rapidly with the increase of he ratio $q_{R}^{\prime \prime} / q_{N H}^{\prime \prime}$. At $q_{R}^{\prime \prime}{ }^{\prime} q_{N H}^{\prime \prime}=15, N u$ falls to about 3 and remains almost constant with further increase of peakediness of the surface heat flux. Therefore, the more peaked the surface heat flux is, the less effective becomes the perpendicular magnetic field in increasing the heat transfer.

In Fig. 7 , the curve for $m=2$ slows that at $q_{R}^{\prime \prime} / q_{N H}^{\prime \prime}=0, N u=4.36$ which is the Nusselt number for parabolic velocity profile and constant surface heat flux. With the increase of the ratio $q_{R}^{\prime \prime} / q_{N H}^{\prime \prime}$, the Nusselt number decreases and reaches a value of 2.7 for highly peaked surface heal flux. It can he noted that for paralsolic velocity 
profile, the effect of peakedness of the surface heat flux in reducing the Nusselt number is less pronoumced compared to that for nearly flat velocity profile $(m=250)$. The maximum reduction of $N u$ for parabolic velocity profile is alsout $37 \%$, whereas it. is about $62 \%$ for nearly flat velocity profile. Another point that should be noted is that, when the surface heat flux is highly peaked, the difference between the Nusselt. numbers for parabolic velocity profile and nearly slug flow is small, about $10 \%\{2.7$ compared to 3 ). This signifies that the nonuniformity of the surface heat fux is nore effective in reducing the Nusselt number or increasing the film temperature drop in the presence of a perpendicular magnetjc field than in the absence of it (parabolic profile).

In the thermal-hydraulic and structural design of the first wall, limiter/divertor plates and blanket of a fusion reactor, the effects of nonuniformity of surface heat flux, volumetric heat generation in the coolant, and perpendicular magnetic field can be siguificant and should be included for a safe design. As an exa:iple of these effects, we can look at the various film temperature drops for laminar flow in the first-wall coolant tube of TITAN-I. The surface heat flux and the volumetric heat generation rates in the wall material and coolant are as mentioneri above. At the point of maximum surface heat flux, $\theta=0^{\circ}$, the film temperature drops are $317^{\circ} \mathrm{C}$. for parabolic profile and $278^{\circ} \mathrm{C}$ for nearly flat profile. If the effect of nonumiformity of the surface heat flux is neglected, these two film temperature drops would become $196^{\circ} \mathrm{C}$ and $104^{\circ} \mathrm{C}$, respectively. The amount of underestimation is quite large. The film temperature drops due to volumetric heat generation are $21^{\circ} \mathrm{C}$ for parabolic profile and $9.7^{\circ} \mathrm{C}$ for nearly flat profile. This temperature drop, which appears not to be included in fusion design, call be quite large for coolants with low thermal conductivity such as FLiBe. 


\section{CONCLUSIONS AND RECOMMENDATIONS}

The effects of nonuniform surface heat flux, uniform volumetric heat generation and velocity profile on the film tesuperature drop in fully developed laminar flow in a circular tube are discussed by deriving an analytical solution. The velocity profile of the coolant is represented by a power law which can be used to represent the flattening of the profile by a perpendicular magnetic field if the coolant is electrically conducting. The following conclusions can be drawn from this analysis.

1. The flattening of velocity profile increases the heat transfer through a reduction of the thickness of the boundary layer. With constant surface heat flux, the Nusselt number increases by $83 \%$ (from $48 / 11$ to 8 ) from parabolic to nearly flat velocity profile. The Nusselt number corr sppondir. 6 to uniform volunetric heat generation, defined by equation (15), increases by $117 \%$ (from $32 / 13$ to $16 / 5)$.

2. The nonuniformity of surface heat flux decreases the Nusselt number at the point of maximum heat flux. With the increase of peakedness of the surffce heat fiux according to equation (17), the Nusselt number decreases from 4.36 to 2.7 for parabolic velocity profile, and from 8 to 3 for nearly siug flows.

3. The point (2) above infers that the effect of nonuniformity of the surface heat flux is more pronounced for fiat velocity profile than for paraloolic profile. Therefore, the heat transfer in liquid-metal coolant in the presence of a perpendicular magnetic field in a fusion reactor will be significantly affected by the nonuniformity of the surface leat flux.

The results obtained in this paper have significant implications for the design of coolant channels for the removal of thermal energy from the first wall, limiter/divertor plates, and blanket of a fusion reactor. The sturface heat fux varies along the circumference of the coolant channels for the first wall and divertor/limiter plates due to the incidence of radiation from the plasma. The maximum wall temperatures of the coolant channels for the first wall and divertor/liniter plates will 
be severely underentimated if the effect of nonuniformity of the surface heat flux is not taken into account. This is particularly important when the surface heat flux is high and the coolant is electrically conducting so that the velocity profile becomes nearly flat due to the effect of a large perpendicular magnetic field.

It appears that the component of the film temperature drop due to uniform volumetric heat generation in the coolant is not accounted for in the design of the coolant channels for fusion reactors. in a deuteriun/tritium fueled fusion reactor, significant amount of volumetic heat will be generated in the coolant if it is not transparent to the fusion neutrons. In this case, the film temperature drop dne to the volumetric heat generation must be added to obtain the total film temperature drop and to determine the correct cliannel-wall temperature. For liquid-metal coolants, this film temperature drop may not be large because of the higl thermal conductivity of the coolant. On the other hand, if the thermal conductivity of a coolant is low and the volumetric heat generation rate is appreciable, this film temperature drop can be quite large.

The analysis done in this paper is applicable to fully developed laminar flow only. Similar analysis should be done for turbulent flow since the coolent flow is expected to be both laminar and turbulent in the coolant cliannels in different. components of a fusion reactor. Although the magnitudes of these filu temperature drops for turbulent flow may be different from those for laminar flow, the trend is expecied to be the same.

Acknowledgement: This work was supported by the U.S. D.O.E. grant DE-FG0386ER52126. 


\section{REFERENCES}

1. H. F. Popendiek, "Forced Convection Heat Transfer in Pipes with VolumeSource within the Fluid", Chem. Eng. Progr. Symposium Ser., vol. 50, No. 11, (1954), pp-93-104.

2. W. C. Reynolds, J. Heat Transfer, Trans. ASME 82 (2) (196), pp108-112.

3. J. H. Holroyd and J. T. M. Mitchell, "Liquid Lithitum as a Coolant for Tokamak Fusion Reactors", Culham Lab. Report CLM-R231 (1982).

4. J. C. R. Hunt and R. Hancox, "The Use of Liquid Lithium as Coolant in a Toroidal Fusion Reactor", Culham Lab. Report (1971).

5. F. Najmabadj et al., "The TITAN Reversed-Field-Pinch Fusion Reactor Study - Final Report", UCLA-PPG-1200 (1988).

6. R. R. Gold, Magnetolyydrodynamic pipe flow, Part I, J. Fluid Mech. 13 (1962) pp 505-512.

7. K. Knopp, "Theorie und Anwendung der Unendlichen Reihen", Verlag Von Julius Springer, Berlin (1924), p-378. 


\section{FIGUAE CAPTIONS:}

Figure 1: The three steps in the solution of the convection heat transfer equation with arbitrary surface heat flux.

Figure 2: Cross section of a circular coolant channel showing the dimensions, surface heat flux, volumetric heat generation rates, and temperature drops.

Figure 3: Dependence of Nusselt number on velocity profile (values of $\mathrm{m}$ ). (a) Nusselt number for constant surface heat flux, $N u_{s}$, and (b) Nusselt mumber for uniform volumetric heat generation, $N u_{n}$.

Figure 4: Circumferential variation of Nusselt number due to circumferentially varying surface heat flux.

Figure 5: A schematic of the temperature profile explaining negative Nusselt number and film temperature drop.

Figure 6: Variation of the $N u\left(0^{\circ}\right)$ due to nonuniform surface heat ! $\times$ with m. The peak radiation heat flux at $\theta=0^{\circ}$ is $4.6 \mathrm{MW} / \mathrm{m}^{2}$.

Figure 7: Variation of $N u\left(0^{\circ}\right)$ with $q_{R}^{\prime \prime} / q_{N H}^{\prime \prime}$ for nearly flat $(m=250)$ and parabolic ( $m=2$ ) velocity profiles. The ratio $q_{R}^{\prime \prime} / q_{N H}^{\prime \prime}$ is a measure of the peakedness of the surface heat flux. 
(a) $\left.k_{,} \frac{\partial T}{\partial r}\right|_{r=a}= \begin{cases}q^{\prime \prime}, & \text { for }-\beta \leq \theta \leq \beta ; \\ 0, & \text { for } \beta \leq \theta \leq(2 \pi-\beta) .\end{cases}$

$$
\frac{\partial T}{\partial \theta}=0\left\{\begin{array}{l}
\text { at } \theta=0 \\
\text { and } \theta=\pi
\end{array}\right.
$$

(b) Segmental heiting, $\beta=\Delta w / 2$.
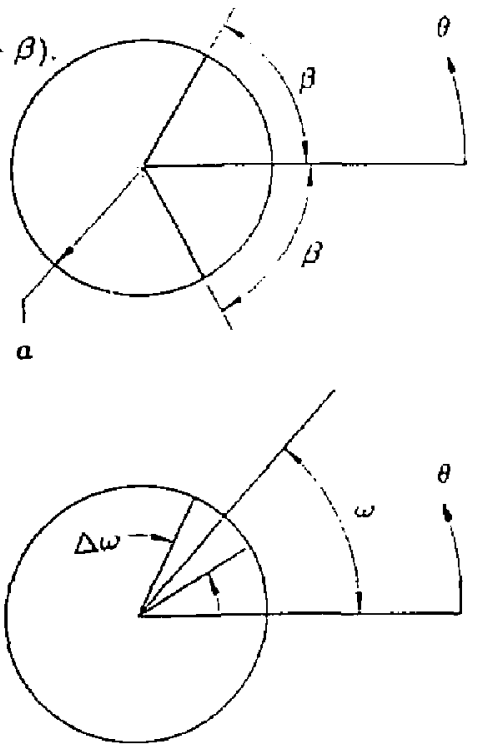

(c) $q^{\prime \prime}(\theta)$ is arbitrar $\because$ function of $\theta$.

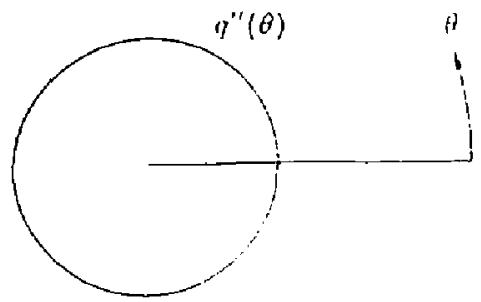

Figure 1. The three steps in the solution of the convection heat transfer equation with arbitrary surface jeat fux. 

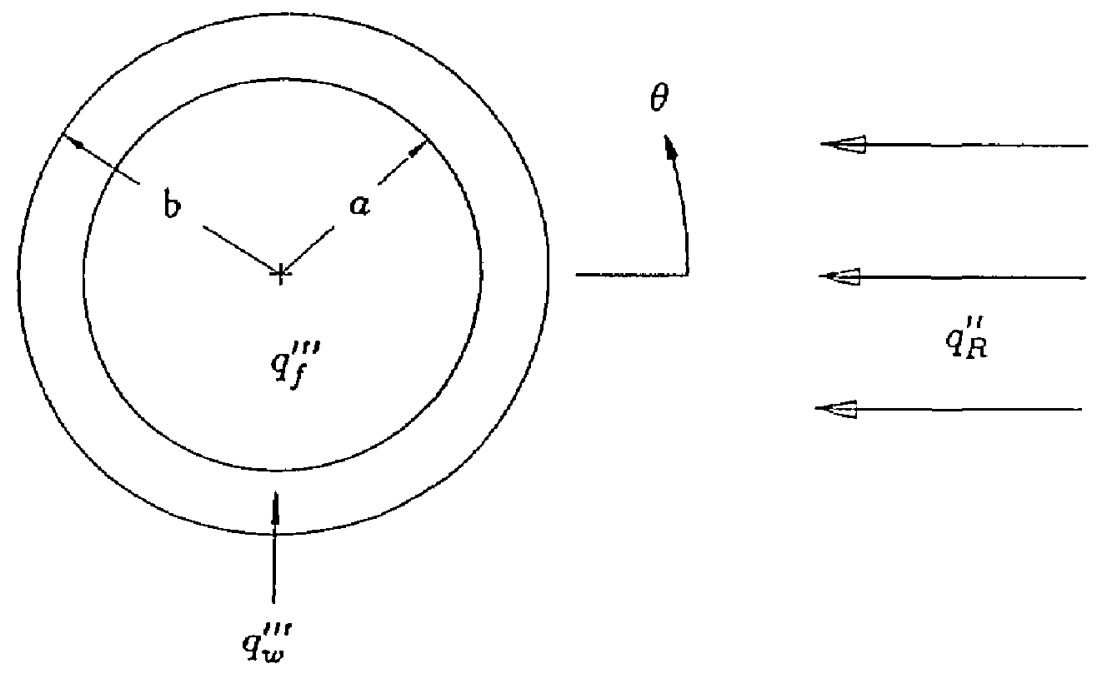

Figure 2. Cross section of a circular coolant chamnel slowing the dimensions, surface heat flux, volunetric heat generation rates, and temperature drops. 


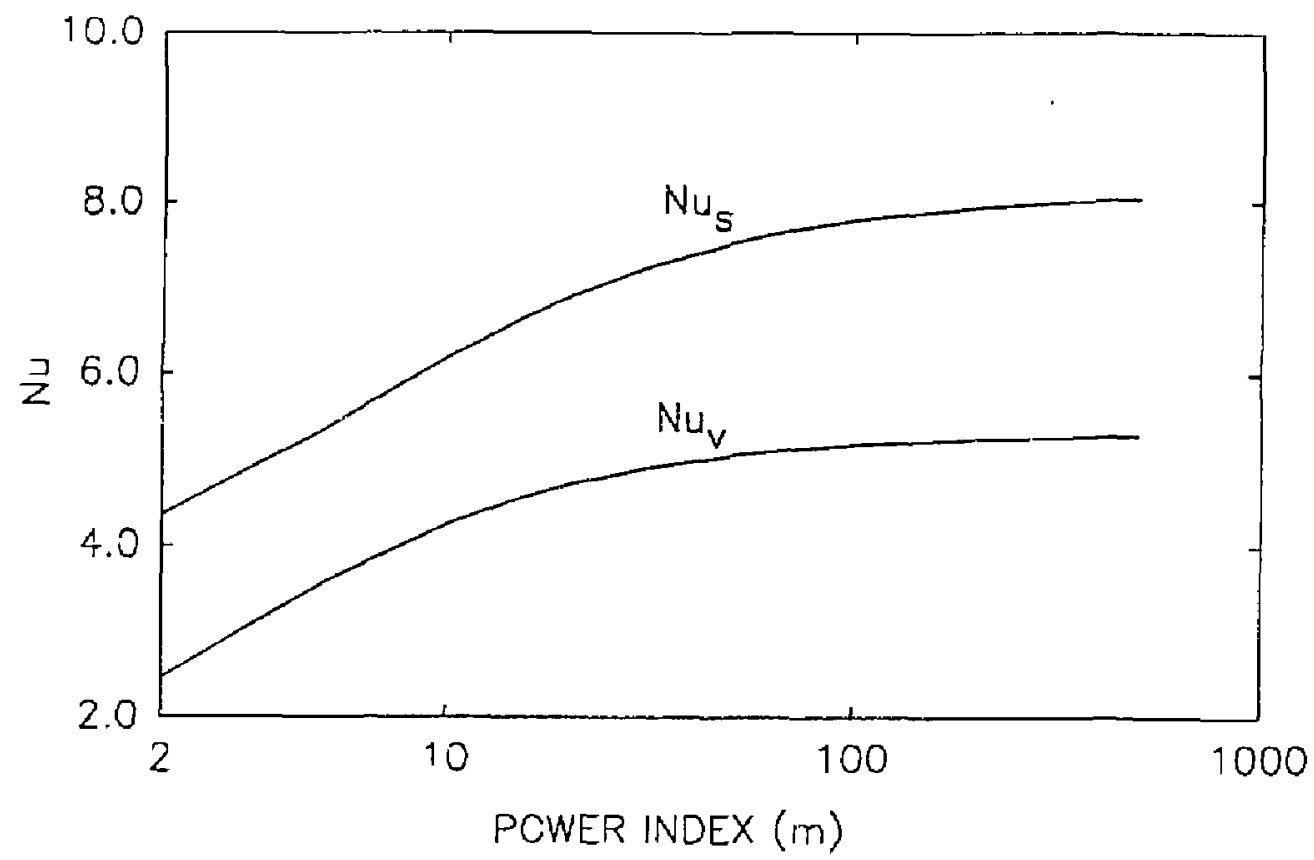

Figure 3. Dependence of Nusselt number on velocity profile (values of $m$ ). (a) Nusselt number for constant surface heal flux, $N_{3}$. and (b) Nusselt number for uniform volumetric heat generation, $N u_{r}$. 


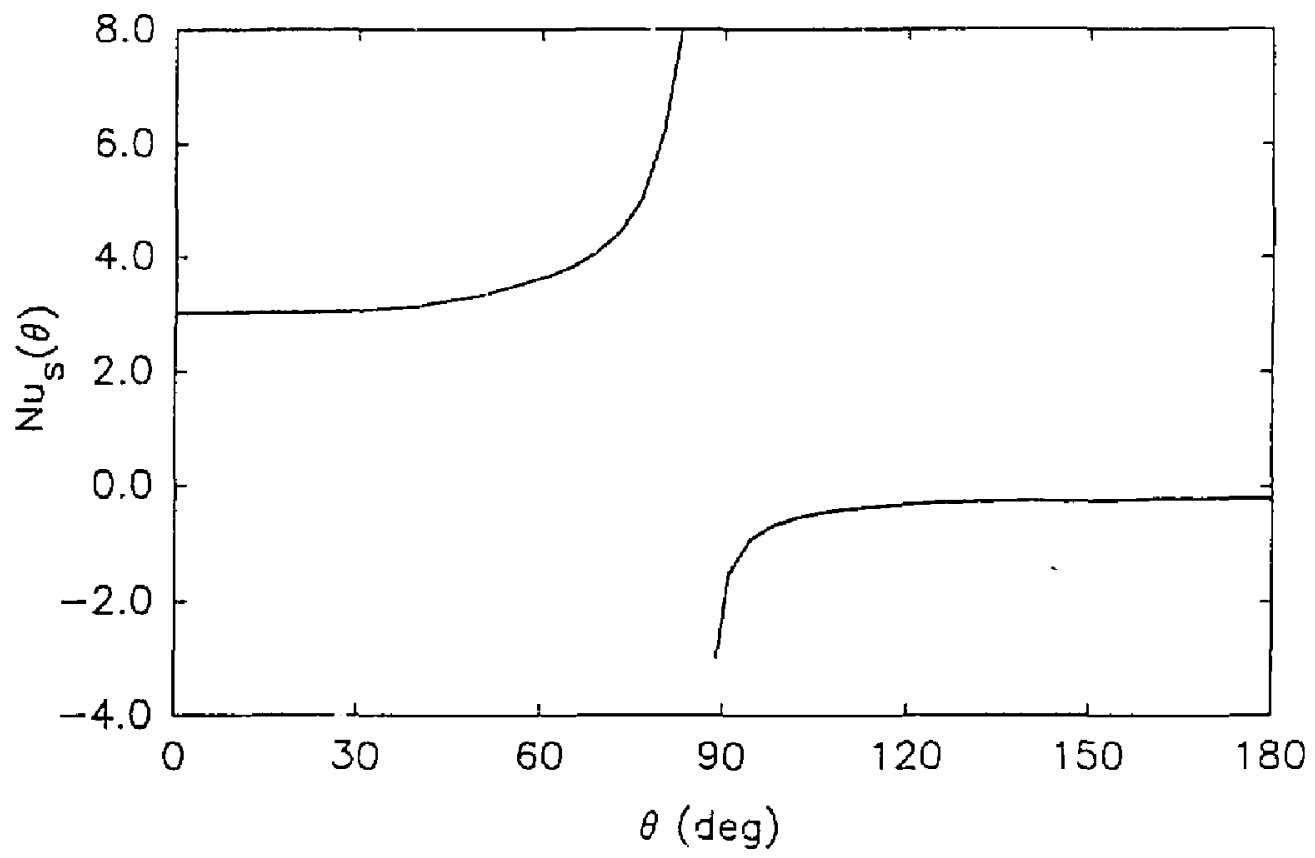

Figure 4. Circumferential variation of Nusselt number due to circumferentially varying surface heat flux. 

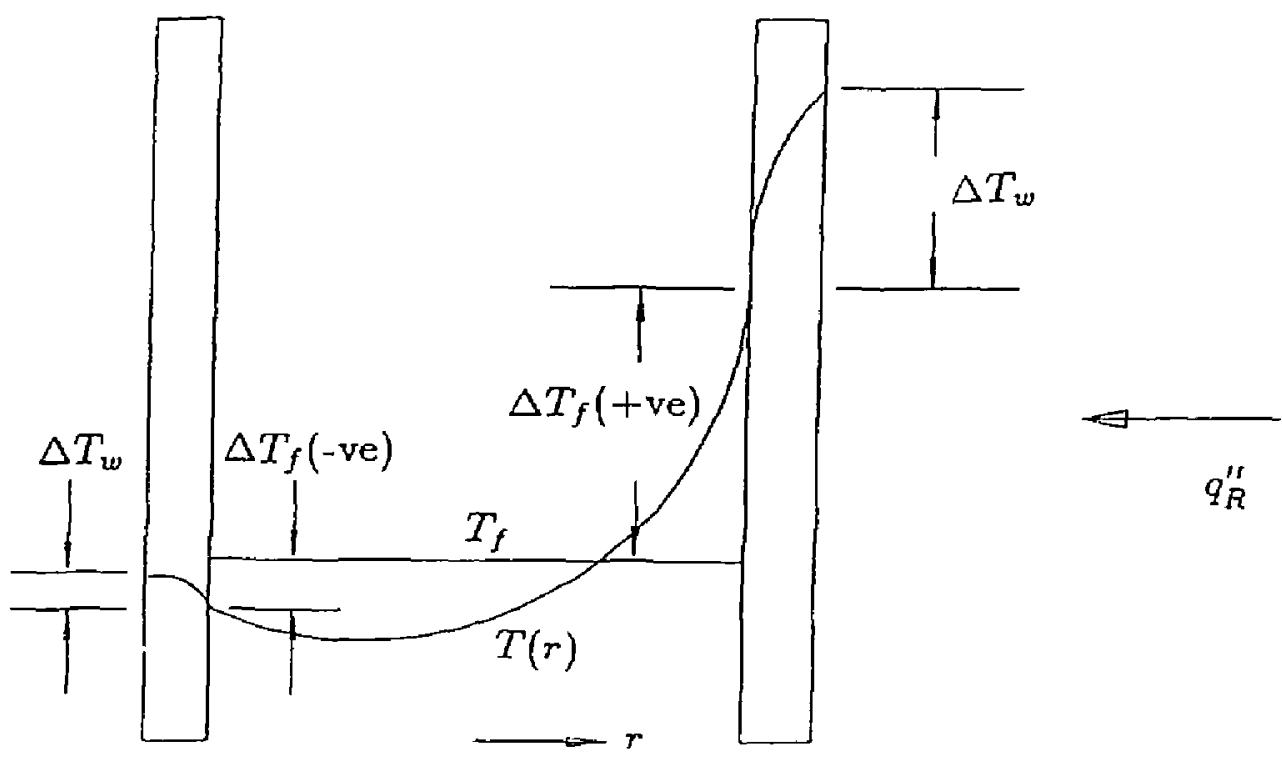

$$
q_{R}^{\prime \prime}
$$

Figure 5. A schematic of the temperature profile explaining negative Nusselt number and film temperature drop. 


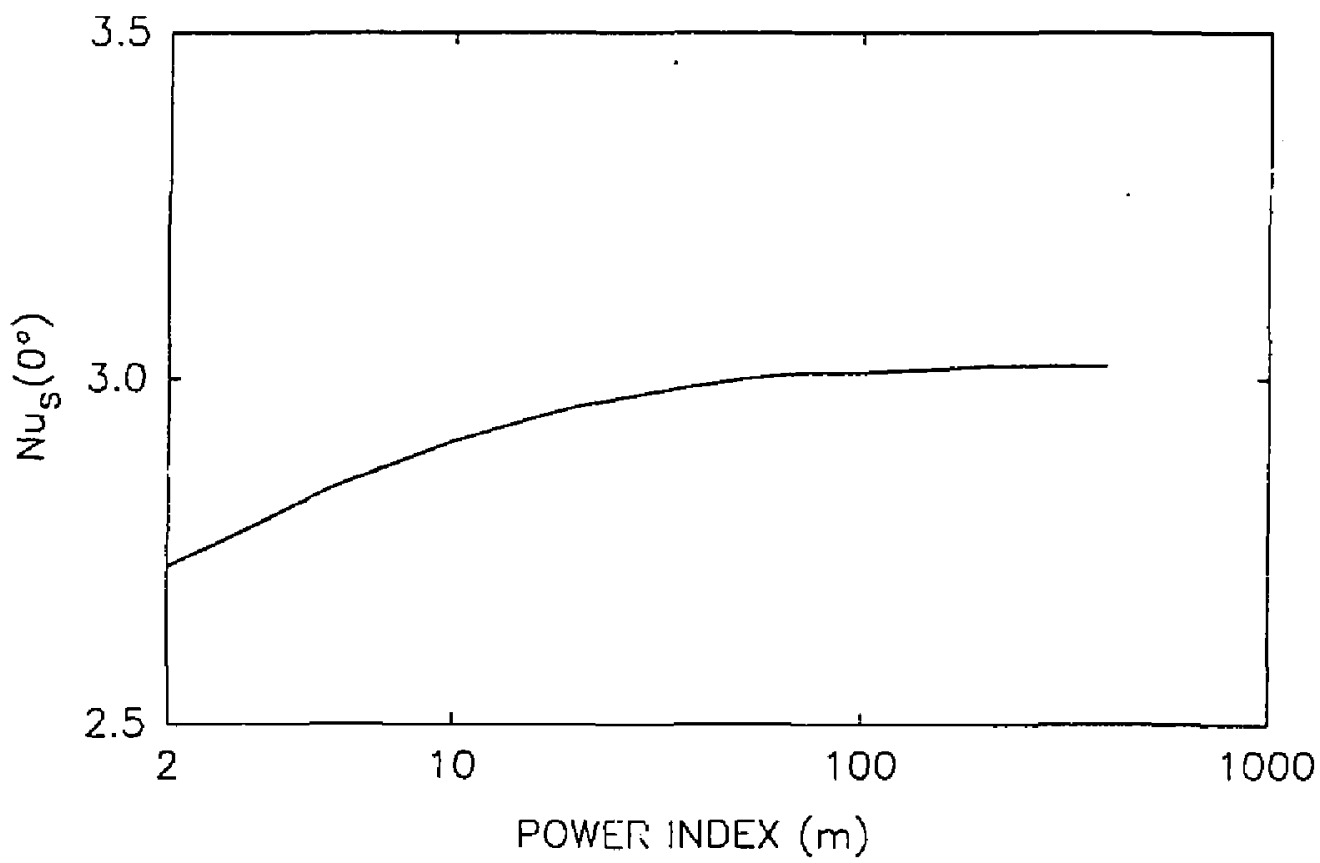

Figure 6. Variation of the $N v\left(0^{\circ}\right)$ due to nonumiform sirface heat flux with m. The peak radiation lieat flux at $\theta=0^{\circ}$ is $4.6 \mathrm{MW} / \mathrm{m}^{2}$. 


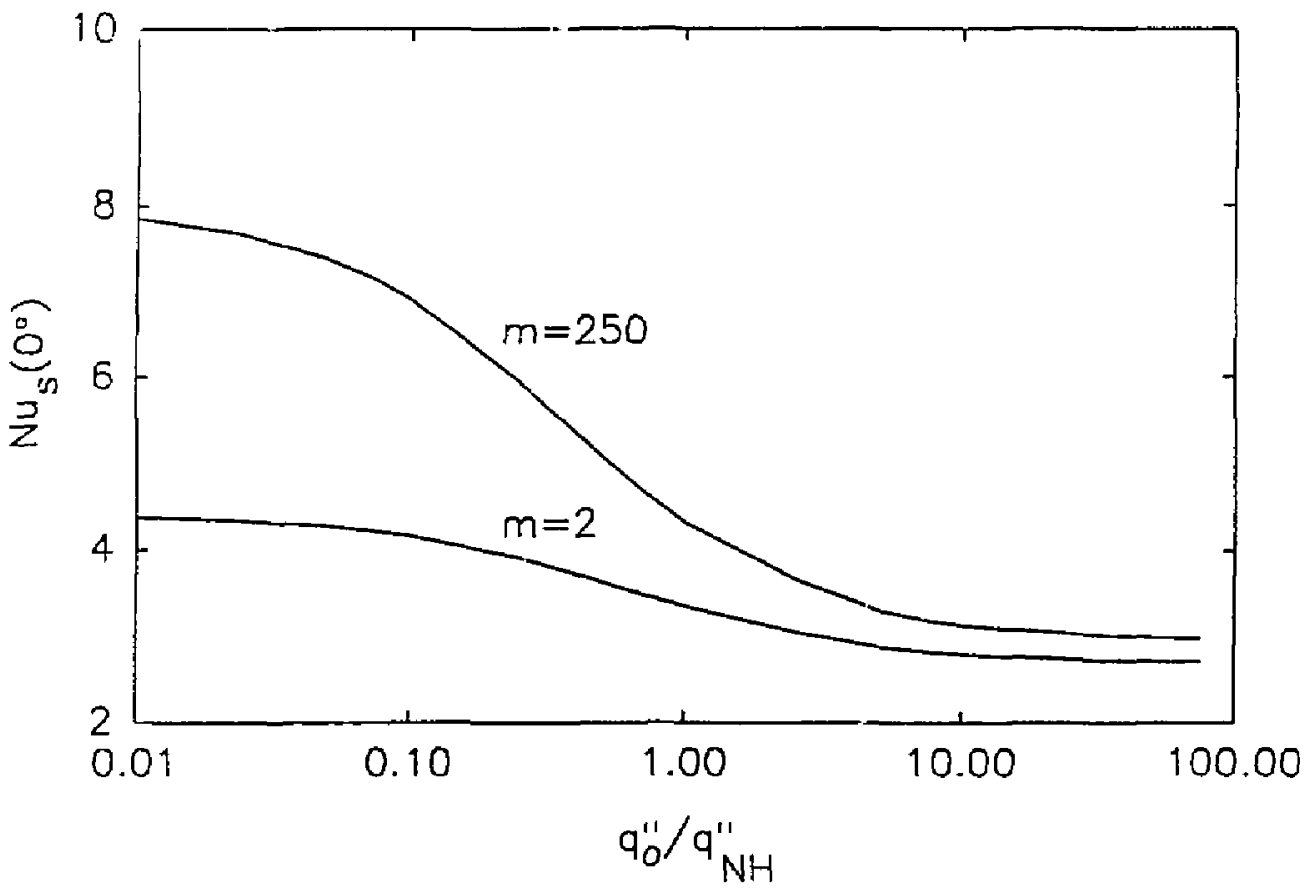

Figure 7. Variation of $N u\left(0^{\circ}\right)$ with $q_{R}^{\prime \prime} / q_{N H}^{\prime \prime}$ for nearly flat $(m=250)$ and paraholic $(m=2)$ velocity profiles. The ratio $q_{R}^{\prime \prime} / q_{N H}^{\prime \prime}$ is a measure of the peakedness of the surface heat flux. 